\title{
DESEMPENHO ORGANIZACIONAL
}

NO SETOR BANCÁRIO BRASILEIRO:

\section{UMA APLICAÇÃO DA ANÁLISE ENVOLTÓRIA DE DADOS}

ORGANIZATIONAL PERFORMANCE ON BRAZILIAN BANK SECTOR: A DATA ENVELOPMENT ANALYSIS APPLICATION

MARCELO ALVARO DA SILVA MACEDO PPGEN/NEGEN/UFRuraIRJ Rod. BR 465, Km 7 - UFRuralRJ/ICHS/DCAC - Seropédica - RJ - CEP 23890-000 E-mail: alvaro@ufrri.br RODRIGO MELO SANTOS NEGEN/UFRuraIRJ Rod. BR 465, Km 7 - UFRuralRJ/ICHS/DCAC - Seropédica - RJ - CEP 23890-000 E-mail: rodrigo@ufrri.br

\section{FABRÍCIA DE FARIAS DA SILVA} NEGEN/UFRuralRJ

Rod BR 465, Km 7 - UFRuralRJ/ICHS/DCAC - Seropédica - RJ - CEP 23890-000 E-mail: fabricia@ufrri.br 


\section{RESUMO}

A análise de desempenho de uma organização é sempre algo passível de muitas discussões. Questionamentos sobre quais indicadores utilizar e como consolidá-los de forma a estabelecer um critério justo de avaliação de performance estão presentes em vários estudos e no dia-a-dia das empresas. É nesse sentido que se apresenta este trabalho como uma proposta de modelagem deste problema, por intermédio da utilização da Análise Envoltória de Dados (DEA). Busca-se um índice de performance relativa que seja capaz de conjugar indicadores financeiros de liquidez, de custo, de risco e de rentabilidade na análise de desempenho organizacional. Em outras palavras, o índice de cada empresa é uma combinação integrada de vários vetores de desempenho e é função não só de sua performance, mas também do desempenho das outras empresas analisadas. Fizeram parte da amostra desta pesquisa bancos de quatro segmentos: 20 bancos de varejo, 34 de atacado, 2 I de middle market e 26 de financiamento, que estavam em operação no Brasil em 2003, listados no ranking da revista Balanço Financeiro da Gazeta Mercantil, sobre o desempenho dos melhores bancos e outras instituições financeiras. Os resultados mostram que tanto os gigantes quanto as pequenas e médias instituições têm totais condições de sobrevivência e de competição, pois não é o tamanho que gera a competitividade no setor, mas sim o desempenho superior.

\section{PALAVRAS-CHAVE}

Performance de bancos; Eficiência; DEA; Desempenho organizacional; Setor bancário.

\section{ABSTRACT}

The organizational performance analysis is always something a matter of a lot of discussions. Questions on which indicators to use and how to consolidate them in way to establish a fair criteria of performance evaluation is present in several studies and in the companies' daily routine. In this way that this work is proposed with a modeling proposal of this problem through the use of the Data Envelopment Analysis (DEA). A relative performance index that is capable to 
conjugate financial indicators of liquidity, cost, risk and profitability in the analysis of organizational performance is searched. In other words, the index of each company is an integrated combination of several performance vectors and it is function not only of its performance, but also of the performance of the other analyzed companies. The research sample were composed of banks of four segments: 20 retail banks, 34 wholesale banks, 2I middle market banking and 26 financing banks, that were in operation in Brazil in 2003, listed in the ranking of the Gazeta Mercantil - Balanço Financeiro Magazine about the performance of the best banks and other financial institutions. The results show that as much the giants as the small and middle institutions have total survival and competition conditions, because it is not the size that produces the competitiveness in the sector, but the superior performance.

\section{KEYWORDS}

Banks performance; Efficiency; DEA; Organizational performance; Bank sector.

\section{INTRODU ÇÃ O}

De acordo com Barr et al. (2002), nas indústrias competitivas, as unidades de produção podem ser separadas em dois grupos distintos, sendo eles eficientes e ineficientes, obedecendo a um padrão de avaliação de desempenho. Essas informações podem auxiliar numa análise de performance, pois são capazes de identificar melhores e piores práticas, que estão relacionadas com alta e baixa eficiência.

Segundo Al-Shammari e Salimi (I998), muitas técnicas de avaliação de performance, envolvendo índices, têm sido usadas intensivamente. No entanto, uma grande quantidade delas apresenta problemas durante algumas etapas de sua execução, fornecendo resultados que podem levar a conclusões errôneas e/ou distorcidas. Todas essas dificuldades induziram alguns pesquisadores a buscar novas alternativas para medir consistentemente a eficiência de determinadas instituições. A Análise Envoltória de Dados (DEA), que consiste em uma técnica de programação matemática, foi uma solução encontrada.

Com a globalização dos mercados, destacam Soteriou e Zenios (I999), na oferta por serviços financeiros têm surgido muitas oportunidades e também uma forte competição nesse setor. Nessa conjuntura é difícil encontrar uma instituição bancária que não esteja voltada à redução de custos, à eliminação de desperdícios de qualquer natureza e à qualidade nos serviços prestados.

Para atender a essas necessidades, ressaltam os autores, é necessária a utilização de alguma modelagem para o problema de desempenho organizacional. 
Nesse sentido, pode ser usada a técnica não-paramétrica de benchmarking conhecida como Análise Envoltória de Dados (DEA), que tem sido aplicada satisfatoriamente nesse setor.

Macedo (2004a) diz que a DEA envolve o uso de métodos de programação linear para construir uma fronteira não-paramétrica sobre os dados, em que medidas de eficiência são calculadas em relação a sua fronteira.

Segundo Zhu (2000) a DEA é uma técnica baseada em programação linear projetada para estabelecer uma medida de eficiência relativa entre diferentes entidades de um gênero comum. Ainda para o autor, a medida de eficiência DEA contabiliza explicitamente o mix de entradas e saídas.

Lins e Meza (2000) colocam que a abordagem analítica rigorosa aplicada à medida de eficiência é tal que nenhum dos outputs pode ser aumentado sem que algum outro output seja reduzido ou algum input necessite ser aumentado; e nenhum dos inputs possa ser reduzido sem que algum outro input seja aumentado ou algum output seja reduzido.

Charnes et al. (1994) ressaltam a necessidade de tratar esta abordagem com um conceito relativo: eficiência de Io०\% é atingida por uma unidade quando comparações com outras unidades relevantes não provêem evidência de ineficiência no uso dos inputs e/ou outputs.

É nesse contexto que se insere este trabalho, que aplica a DEA na avaliação do desempenho de bancos em operação no Brasil em 2003. A partir de informações sobre liquidez imediata, inadimplência, eficiência operacional, rentabilidade do patrimônio líquido e custo operacional de bancos de quatro segmentos, de varejo, de atacado, de middle market e de financiamento, busca-se discutir a performance relativa dessas empresas, bem como a utilidade da modelagem apresentada.

Assim sendo, este artigo tem como objetivo analisar o desempenho de bancos em operação no Brasil no ano de 2003, utilizando variáveis contábil-financeiras, conjugadas com o uso da DEA. Além disso, este trabalho tem o propósito de analisar a aplicabilidade da DEA em estudos sobre desempenho de empresas.

\section{ANÁlise envoltória de dados (DEA )}

De acordo com Camargo Jr. et al. (2004), análises de eficiência de sistemas produtivos implicam o estudo e o levantamento de fronteiras de produção, que apresentam o conjunto de unidades produtivas que, dado um paradigma tecnológico, obtém máxima quantidade de produto para um conjunto de insumos e são consideradas eficientes quando comparadas a outras unidades de produção similares. 
A fronteira, destacam os autores, separa duas regiões: a de inviabilidade tecnológica, já que não seria possível, dadas as restrições tecnológicas do momento, alcançar um nível de produção maior do que aquele da fronteira para um dado nível de alocação de fatores de produção, e a região de ineficiência, que contém organizações que apresentam um nível de produção menor do que aquele da fronteira para um dado conjunto de fatores de produção. Uma medida de ineficiência pode ser considerada como a distância entre a observação da unidade ineficiente e a fronteira.

A obtenção das fronteiras, continuam os autores, pode ser feita por dois grupos de técnicas diferentes: baseadas em buscas paramétricas ou não-paramétricas. As técnicas paramétricas baseiam-se na estimação das fronteiras por meio de métodos estatísticos e/ou econométricos, em que algumas hipóteses são necessárias para a calibração dos modelos. Já as técnicas não-paramétricas buscam o levantamento das unidades consideradas eficientes por meio da resolução de problemas de programação linear (PPLs).

Segundo Soteriou e Zenios (I999), DEA é uma técnica de programação matemática originalmente proposta por Charnes et al. (1978). Esta pretende avaliar a eficiência relativa de um número de unidades homogêneas, transformando entradas em saídas. Uma unidade é considerada eficiente (taxa de eficiência igual a ı००\%) se nenhuma outra no conjunto de dados puder produzir mais saídas usando a mesmas entradas ou as mesmas saídas usando menos entradas. Além disso, DEA pode fornecer índices com base no desempenho das melhores unidades para aquelas que foram consideradas ineficientes. Esses índices serão utilizados como referência para melhorar seu desempenho. Ainda de acordo com os autores, a popularidade desse método se elevou substancialmente durante a década de I990, sendo principalmente utilizado nos estudos de medição de eficiência.

Segundo Antunes de Oliveira e Tabak (2004), o modelo DEA consiste em uma abordagem de programação matemática não-paramétrica para estimação de uma fronteira linear de produção, que pode ser aplicada para avaliar a eficiência relativa de uma variedade de instituições produtoras de tarefas similares, definidas como unidades de tomada de decisão (DMUs - Decision Making Units), utilizando uma variedade de dados como insumos (inputs) e produtos (outputs). O DEA pode transformar múltiplas medidas de insumos e produtos em uma simples estimativa de eficiência. Em outras palavras, o DEA é formado como uma combinação linear que conecta o conjunto de melhores práticas observadas produzindo um conjunto de possibilidades de produção convexo. Uma das principais vantagens do DEA é que não há necessidade de especificar uma forma funcional particular para a fronteira de produção.

Segundo Barr et al. (2002), muitas têm sido as tentativas de avaliar da melhor forma possível o desempenho de algumas instituições, e não há um consen- 
so entre os pesquisadores de qual método seja mais apropriado. Em geral, as metodologias paramétricas especificam uma "forma funcional" para os custos e lucros ou relações de produção entre entradas e saídas. A metodologia DEA, nãoparamétrica, é um método para a delimitação da fronteira eficiente, porque ao focalizar a eficiência da relação entre inputs e outputs não requer a especificação explícita da forma dessa relação. Assim, DEA tem provado ser uma ferramenta valiosa em processos decisórios estratégicos. Esta vem sendo usada como um instrumento analítico e quantitativo de benchmarking para medir a eficiência relativa entre empresas, particularmente no setor bancário.

De acordo com Camargo Jr. et al. (2004), a grande vantagem da obtenção da fronteira eficiente por uma técnica não-paramétrica, como a modelagem DEA, é que esta não necessita de hipóteses sobre as funções de produção das empresas analisadas, como seria necessário no caso da adoção de alguma das técnicas paramétricas. Entretanto, a fronteira obtida simplesmente retrata eficiências relativas entre as várias unidades produtivas analisadas, não podendo ser encarada como a verdadeira fronteira eficiente para todo o setor industrial estudado, por exemplo. A fronteira poderá se alterar com a introdução e/ou retirada de quaisquer empresas do modelo construído.

Ainda segundo os autores, a metodologia DEA consiste em estabelecer uma hierarquização relativa entre as organizações estudadas com base em índices de produtividade obtidos de formulações de problemas de programação linear (PPLs).

Al-Shammari e Salimi (1998) dizem que DEA é uma metodologia, baseada em programação linear, utilizada para calcular a eficiência relativa de um grupo de entidades ou unidades homogêneas, que usam múltiplas entradas para produzir múltiplas saídas, quando a forma da produção não é conhecida ou especificada, como no caso da abordagem paramétrica. O modelo busca unidades eficientes que servem de base de benchmarks para as outras unidades.

Ainda, segundo os autores, uma unidade pode ser julgada relativamente ineficiente se a unidade-base utilizar menos entradas para obter as mesmas saídas alcançadas por essa unidade, ou se utilizar as mesmas entradas para alcançar mais saídas do que a unidade em questão. Assim, as unidades consideradas ineficientes poderão adotar os índices da unidade-base, de forma que suas ineficiências sejam minimizadas. Os resultados obtidos por meio dessa metodologia auxiliam a identificação daquelas unidades passíveis de melhorias e fornece meios para melhorar sua performance.

Segundo Camargo Jr. et al. (2004), as técnicas não-paramétricas, como a modelagem DEA, permitem a obtenção da fronteira eficiente, baseada em programação matemática, da qual se obtêm as unidades eficientes, à medida que apresentam níveis máximos de produção (variáveis de saída) dada uma certa restrição de emprego de fatores de produção (variáveis de entrada). 
A DEA, segundo Zhu (2000), representa uma das mais adequadas ferramentas para avaliar a eficiência, em comparação com ferramentas convencionais. Os resultados de DEA são mais detalhados do que os obtidos em outras abordagens, servindo melhor ao embasamento de recomendações de natureza gerencial. Sendo assim, os autores destacam as seguintes características dessa ferramenta:

- não requer a priori uma função de produção explícita;

- $\quad$ examina a possibilidade de diferentes, mas igualmente eficientes, combinações de inputs e outputs;

- localiza a fronteira eficiente dentro de um grupo de unidades analisadas; e - determina, para cada unidade ineficiente, subgrupos de unidades eficientes, os quais formam seu conjunto de referência.

De acordo com Macedo (2004b), a DEA é uma técnica de pesquisa operacional, que tem como base a programação linear, e cujo objetivo é analisar comparativamente unidades independentes (empresas, departamentos etc.) no que se refere ao seu desempenho. Ela fornece uma medida para avaliar a eficiência relativa das unidades de tomada de decisão (DMUs), que são as unidades cuja eficiência está sendo avaliada. Cada DMU é representada por um conjunto de $\underline{S}$ outputs e um conjunto de $\underline{\mathrm{M}}$ inputs. A idéia básica é a comparação dos outputs com os inputs.

Segundo Charnes et al. (I994), essa abordagem permite diferenciar entre estados de produção eficientes e ineficientes, já que os modelos de programação matemática provêem uma maneira elegante de, simultaneamente, construir a fronteira para um dado conjunto de unidades analisadas e calcular a distância da fronteira a cada uma das observações individuais.

Para Macedo (2004a), a resposta mais importante dessa metodologia é a caracterização de uma medida de eficiência, que faz com que a decisão fique orientada por um único indicador construído a partir de várias abordagens de desempenho diferentes. Vale ressaltar que isso facilita em muito o processo decisório, pois, em vez de considerar vários índices para concluir a respeito do desempenho da empresa ou da unidade sob análise, o gestor utiliza apenas da medida de eficiência do DEA. Além disso, existem outras informações oriundas dessa metodologia que podem ser utilizadas para auxiliar a empresa na busca pela excelência.

São várias as formulações dos modelos de DEA encontradas na literatura, conforme dizem Charnes et al. (I994); entretanto, dois modelos básicos DEA são geralmente usados nas aplicações. O primeiro modelo, chamado de CCR (CHARNES, COOPER; RHODES, I978), também conhecido como CRS (Cons- 
tant Returns to Scale), avalia a eficiência total, identifica as DMUs eficientes e ineficientes e determina a que distância da fronteira de eficiência estão as unidades ineficientes. O segundo, chamado de modelo BCC (BANKER, CHARNES; COOPER, I984), também conhecido como VRS (Variable Returns to Scale), utiliza uma formulação que permite a projeção de cada DMU ineficiente sobre a superfície de fronteira (envoltória) determinada pelas DMUs eficientes de tamanho compatível.

No caso das formulações, além das da escolha entre CRS e VRS (neste estudo trabalharemos com a formulação DEA-CRS), existe a necessidade de fixação da ótica de análise (orientação input ou orientação output).

De acordo com Camargo Jr. et al. (2004), a abordagem DEA baseada nas entradas (inputs) busca maximizar as quantidades de produtos, isto é, maximizar uma combinação linear das quantidades dos vários produtos da empresa. Ou seja, a modelagem busca encontrar os pesos para cada produto, de forma que a combinação linear dos produtos seja máxima. Já para uma abordagem baseada nas saídas (outputs), busca-se minimizar as quantidades de insumos, isto é, minimizar uma combinação linear das quantidades dos vários insumos da empresa. Ou seja, a modelagem busca encontrar os pesos para cada insumo, de forma que a combinação linear dos insumos seja mínima.

Além disto, ressaltam os autores, faz-se necessária a restrição de que, com esses pesos encontrados, as eficiências de cada uma das outras empresas da amostra não sejam superiores a um. Assim, podemos obter, para cada empresa da amostra, uma família de pesos que faz com que sua eficiência seja máxima e comparar tal eficiência com as demais empresas simplesmente pela utilização desses mesmos pesos.

Segundo Lins e Meza (2000), alguns analistas tendem a selecionar modelos com orientação input porque, em muitos casos, tem-se outputs estabelecidos para se alcançar e, portanto, as "quantidades" de inputs apresentam-se como variáveis de decisão primária. Porém, existem outras situações em que se poderia ter uma quantidade fixada de inputs (inalterados) e poder-se-ia estar procurando como "produzir" mais outputs. Nesse caso, uma orientação output poderia ser mais apropriada, na qual o objetivo é maximizar os "produtos" obtidos sem alterar o nível atual dos inputs.

De acordo com Macedo (2004b), os modelos utilizados, desenvolvidos a partir do DEA, são capazes de conjugar em um único índice vários indicadores de natureza diferentes para a análise do desempenho organizacional. Pode-se perceber, então, que a modelagem possui as características de trabalhar diversas variáveis sem a necessidade de convertê-las para um padrão comum de unidade e de apoiar o processo decisório com uma técnica de natureza multicritério e, portanto, mais capaz de modelar a complexidade do mundo real. 
De acordo com Coelli et al. (1998), Charnes, Cooper e Rhodes (I978) propuseram um modelo que tinha uma orientação input e assumia retornos constantes de escala (CRS). Artigos subseqüentes têm considerado várias alternativas, dentre elas as de Banker, Charnes e Cooper (I984), em que o modelo de retorno variável de escala (VRS) foi proposto.

Assim, ainda segundo Coelli et al. (I998), um caminho intuitivo para introduzir DEA é por meio de forma de razão. Para cada DMU, gostaríamos de obter uma medida de razão de todos os outputs sobre todos os inputs, ou seja, os pesos ótimos $u_{j}$ e $v_{i}$ são obtidos pela resolução do seguinte problema de programação matemática:

$$
\begin{aligned}
\operatorname{Max} E_{c}= & \frac{\sum_{j=1}^{s} u_{j} y_{j c}}{\sum_{i=1}^{m} v_{i} x_{i c}} \\
\text { S.a.: } \quad & \frac{\sum_{j=1}^{s} u_{j} y_{j k}}{\sum_{i=1}^{m} v_{i} x_{i k}} \leq 1, k=1,2, \ldots, c, \ldots, n \\
& u_{j} \geq 0, \forall j, \\
& v_{i} \geq 0, \forall i
\end{aligned}
$$

Nesse modelo, c é a unidade (DMU) que está sendo avaliada. O problema acima envolve a procura de valores para u e v, que são os pesos, de modo que maximize a soma ponderada dos outputs (output "virtual") dividida pela soma ponderada dos inputs (input "virtual") da DMU em estudo, sujeita a restrição de que esse quociente seja menor ou igual a I, para todas as DMUs. Esta função está sujeita à restrição de que, quando o mesmo conjunto de coeficientes de entrada e saída (os vários $v_{i}$ e $u_{j}$ ) for aplicado a todas as outras unidades de serviço que estão sendo comparadas, nenhuma unidade excederá ı००\% de eficiência ou uma razão de I,००.

Para Antunes de Oliveira e Tabak (2004), o que diferencia o DEA dos enfoques paramétricos é que os escores de eficiência do DEA produzidos para cada DMU não podem ser definidos por um padrão absoluto, mas em função das outras DMUs, enquanto os modelos paramétricos requerem uma forma funcional preestabelecida das funções de produção.

Ainda de acordo com os autores, a medida de eficiência utilizada pelo DEA é a relação da soma ponderada dos produtos com a soma ponderada dos insumos. Para cada DMU, então, um conjunto de pesos é determinado, a fim de 
mostrar a melhor possibilidade. Podemos pensar no DEA como uma medida de eficiência relativa para cada DMU, maximizando a relação dos produtos pelos insumos, sujeita à condição de que relações similares para cada DMU não sejam maiores que I.

Para Macedo (2004a), o modelo original CCR, também conhecido como CRS, segundo a ótica dos multiplicadores, pode ter um índice de eficiência definido, então, como a combinação linear dos outputs dividida pela combinação linear dos inputs de determinada DMU. Porém, um problema como esse, de formulação fracionária, possui infinitas soluções ótimas.

Segundo Antunes de Oliveira e Tabak (2004), essa relação é uma função não-linear e fracionária que possibilita gerar pesos positivos que maximizam a relação produto/insumo de cada DMU. Pode-se resolver esse problema de programação não-linear de difícil solução transformando a relação em uma função linear, simplesmente considerando o denominador (soma ponderada dos insumos) da função objetivo igual a I.

Para evitar isso, segundo Coelli et al. (I998), uma possível imposição seria $\Sigma$ vi xic $=\mathrm{I}$, pois, além disso, queremos linearizar as restrições do problema, de modo a transformá-lo em um Problema de Programação Linear (PPL). Então, introduzindo a transformação linear desenvolvida por Charnes e Cooper (I962), obtemos:

$$
\begin{aligned}
\operatorname{Max} E_{c}= & \sum_{j=1}^{s} u_{j} y_{j c} \\
\text { S.a.: } \quad & \sum_{i=1}^{m} v_{i} x_{i c}=1 \\
& \sum_{j=1}^{s} u_{j} y_{j k}-\sum_{i=1}^{m} v_{i} x_{i k} \leq 0, k=1,2, \ldots, c, \ldots, n \\
& u_{j}, v_{i} \geq 0, \forall x, y .
\end{aligned}
$$

Essa forma do problema é conhecida como problema dos multiplicadores, como também são chamados os pesos $u_{\mathrm{i}} \mathrm{e} \mathrm{v}_{\mathrm{i}}$. Denotamos esse PPL por CRS/M/I.

Esse modelo é utilizado para a análise dos dados, pois temos três inputs e

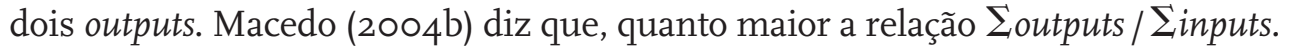
maior a eficiência. Para cada DMU a ser analisada, formula-se um problema de otimização com o objetivo de determinar os valores que essa DMU atribuiria aos multiplicadores u e v de modo a aparecer com a maior eficiência possível.

Então, complementa o autor, o problema consiste em achar os valores das variáveis $u_{\mathrm{j}}$ e $v_{\mathrm{i}}$, que são os pesos (importância relativa de cada variável), de mo- 
do que se maximize a soma ponderada dos outputs (output "virtual") dividida pela soma ponderada dos inputs (input "virtual") da DMU em estudo, sujeita na restrição de que esse quociente seja menor ou igual a um, para todas as DMUs. Logo, as eficiências variam de o a i ou ० \% e roo \%.

Antunes de Oliveira e Tabak (2004) dizem que uma das características do DEA é ser uma medida de eficiência relativa. Ou seja, os escores de eficiência verificados em determinada função somente valem para a amostra em estudo. Caso haja alteração na amostra com inclusão de novas DMUs ou alteração nos insumos e/ou produtos, torna-se necessário calcular novos escores de eficiência. Os resultados de eficiência de determinada amostra não são comparáveis com os resultados de amostras diferentes.

É importante ressaltar também a característica não-paramétrica da metodologia DEA, em que os parâmetros de eficiência são reais e estabelecidos na amostra dentre as instituições que apresentaram melhor performance. Isso não significa que as DMUs mais eficientes de determinada amostra sejam as mais eficientes da população ou, ainda, que não possam aumentar seu nível de eficiência. Essas DMUs simplesmente apresentaram o maior nível de eficiência em relação às demais DMUs da amostra, dentro dos insumos e produtos utilizados, assumindo assim o maior escore possível. Em linhas gerais, caso o indicador de eficiência de determinada DMU seja igual a um, esta estará operando em escala ótima.

\section{ANÁLISE E AVALIAÇÃO dE DESEMPENHO A PARTIR DE INDICADORES CONTÁBIL-FINANCEIROS}

De acordo com Crozatti e Guerreiro (2003), os processos de gestão empresarial, responsáveis pela condução das atividades, tanto em nível estratégico como operacional, têm recebido atenção de maneira mais intensa nos últimos anos, principalmente no que tange a diversidade de conceitos e modelos de mensuração e de avaliação do desempenho construídos no intuito de preparar as organizações para enfrentar os desafios do ambiente competitivo.

Segundo Omaki (2005), considerações sobre desempenho superior e estratégias que permitam alcançá-lo sempre estiveram presentes nas organizações. Entender as razões do sucesso das empresas e os meios que levam as organizações a alcançarem vantagem competitiva sustentável tornou-se uma área de pesquisa de relevante importância nas ciências gerenciais.

Uma vantagem competitiva sustentável, ressaltam Brito et al. (2005), não advém de ações isoladas, ela deriva de decisões estratégicas de criação de valor 
que não estejam sendo simultaneamente implementadas por seus concorrentes e que visem a obter do mercado e da própria empresa as melhores opções.

Nesse contexto, dizem Omaki (2005) e Brito et al. (2005), destaca-se a perspectiva Resource Based View (RBV), que considera as organizações como um conjunto de recursos (ativos, competências e capacidades), fatores determinantes para se atingir performance superior. Porém, nem todos os recursos são estratégicos, ou seja, podem gerar níveis significativos de ganhos ou podem ser protegidos da competição.

Ou seja, cada fator considerado no processo de mensuração de desempenho precisa ser de tal ordem que o sucesso empresarial tenha este como de fundamental importância. Esses seriam pontos críticos ou fatores críticos do sucesso empresarial, que necessitam ser monitorados e, por conta disso, precisamos ter informações confiáveis a respeito de seu comportamento. Estes são, geralmente, os elementos mais significativos da operação da empresa.

Gartner (2005) diz que é possível sintetizar os objetivos básicos a serem alcançados pelo gestores como: maximizar as funções de lucratividade e participação de mercado, que são naturalmente antagônicas em mercados altamente competitivos, ao mesmo tempo que se considera a responsabilidade social da empresa. O monitoramento do alcance desses objetivos pode ser feito por meio de um processo de avaliação de desempenho que tome por base a abordagem das referências de nível (benchmarking). Por essa abordagem, definem-se os critérios de avaliação e comparam-se os resultados alcançados pela empresa com aqueles obtidos pelas melhores empresas do setor. Assim sendo, conclui o autor, tal análise possibilita que os gestores estabeleçam parâmetros de desempenho para indicadores estratégicos globais, especialmente aqueles de mercado e financeiros, o que subsidiará o planejamento dos sistemas de avaliação do desempenho.

O uso de indicadores oriundos de práticas contábil-financeiras, tais como retorno sobre o ativo ou sobre o patrimônio líquido ou ainda sobre as vendas, é importante, mas não consegue traduzir todos os objetivos estratégicos das empresas. Por conta disso, muitos estudos vêm buscando integrar esses indicadores com outros não-financeiros, formando, assim, uma avaliação multidimensional de diversas naturezas do desempenho organizacional.

Segundo Kaplan e Norton (1997), as organizações têm tentado se inserir no mercado competitivo lançando mão de diversas iniciativas de melhoria. Entretanto melhorias de desempenho exigem mudanças também nos sistemas de mediação e gestão utilizados pelas empresas, pois é impossível atingir a excelência empresarial controlando apenas as medidas financeiras do desempenho passado, visto que os executivos necessitam de indicadores sobre vários aspectos do ambiente e desempenho organizacional. 
Para os autores, o ideal seria que o modelo de contabilidade financeira se ampliasse de modo a incorporar a avaliação de ativos intangíveis e intelectuais de uma empresa, porém existe a dificuldade de se atribuir um valor financeiro confiável a esses ativos.

Segundo Machado et al. (2003), as empresas, no passado, tomavam decisões baseadas unicamente em informações financeiras, porém, atualmente, as tomadas de decisão envolvem maior número de variáveis, exigindo uma grande preocupação entre os gestores com indicadores como: satisfação de clientes, qualidade dos produtos, participação no mercado, retenção de clientes, fidelidade dos clientes, inovação, habilidades estratégicas e outros.

Wanderley et al. (2003) dizem que os métodos de avaliação do desempenho empresarial, que se baseiam apenas em indicadores contábeis e financeiros, vêm se tornando insuficientes. É esse contexto que explica o surgimento de diversos modelos de mensuração de desempenho, com o propósito de gerenciar eficientemente as informações corporativas (financeiras e não-financeiras) que dão suporte às tomadas de decisão. Um grande número de empresas está na busca incessante por tais sistemas, gerando assim a necessidade de maiores estudos sobre sistemas de medição de desempenho.

De acordo com Kaplan e Norton (I997), o Balanced Scorecard seria uma possível solução para essa problemática, pois representa um sistema de mensuração com indicadores financeiros e não-financeiros. Suas medidas focalizam o desempenho organizacional sob quatro perspectivas: financeira, do cliente, dos processos internos e de aprendizado e crescimento; equilibrando-se entre medidas objetivas, de resultado e facilmente quantificáveis, e vetores subjetivos, até certo ponto arbitrários, das medidas de resultado.

Os autores destacam que o Balanced Scorecard conserva a perspectiva financeira, pois essas medidas indicam se a estratégia de uma empresa, sua implementação e execução estão contribuindo para a melhoria dos resultados.

Quanto à perspectiva do cliente, estão entre as medidas essenciais de resultado a satisfação, a retenção, a atração e a lucratividade dos clientes. Sendo assim, esta se torna imprescindível, então, para a fidelização destes.

Por intermédio das perspectivas dos processos internos, os gestores identificam os processos internos críticos nos quais a empresa deve alcançar a excelência. As medidas estão voltadas para a qualidade, tempo de resposta, custo e lançamento de novos produtos.

Já a perspectiva do aprendizado e crescimento identifica a infra-estrutura que a empresa deve construir para gerar crescimento e melhoria a longo prazo. Cabem aqui medidas de resultado baseadas nos funcionários, tais como satisfação, retenção, treinamento e habilidade destes.

De acordo com Machado et al. (2003), o uso de medidas não-financeiras e financeiras, auxiliando os administradores a focarem suas ações em perspecti- 
vas de longo e curto prazos, é adequado para orientar e avaliar a trajetória da empresa em um ambiente competitivo. Os indicadores financeiros, como medidas de ocorrência, contam parte, mas não toda a história das ações passadas. Estes, isolados, não são capazes de fornecer orientações adequadas para as ações que devem ser realizadas hoje e amanhã para criar valor financeiro futuro, porém estas não devem ser esquecidas quando da avaliação de resultados e desempenhos, pois são provas concretas dos efeitos de todas as outras medidas.

Ainda segundo Kaplan e Norton (1997), para que um Balanced Scorecard possa ser considerado bem elaborado, é preciso que as diversas medidas que o compõem façam parte de uma série articulada de objetivos e medidas coerentes que se reforcem mutuamente. Essas associações devem incorporar tanto as relações de causa e efeito quanto as combinações de medidas de resultado e vetores de desempenho.

Visto o exposto, pode-se perceber a importância dos fatores financeiros e não-financeiros para a avaliação do desempenho das empresas, já que a ênfase excessiva na obtenção de resultados financeiros pode levar as empresas a investirem demasiadamente em soluções superficiais em detrimento da criação de valor. Além disso, as medidas financeiras podem ser inadequadas para orientar e avaliar a organização em ambientes competitivos.

Porém, de acordo com Omaki (2005), tendo em vista as complexidades de se mensurar o desempenho organizacional, a medida ideal requer uma variedade de indicadores, financeiros e não-financeiros, entretanto as medidas de desempenho utilizadas em seu trabalho são exclusivamente financeiras, pois, apesar das limitações, o uso de medidas de desempenho financeiro ainda é o procedimento mais comum e sobre o qual existem inúmeros estudos comprovando sua validade, ao menos como um estimador razoável do desempenho organizacional. Esse fato é ressaltado também por Lima Faria et al. (2005), que dizem que são muitos os estudos que utilizam medidas tais como retorno sobre o ativo (ROI - Return On Investment) e retorno sobre o patrimônio líquido (ROE - Return On Equity), indicadores financeiros, como únicas variáveis de desempenho organizacional.

Brito e Vasconcelos (2005) destacam que o desempenho tem sido visto, geralmente, como tendo uma natureza multidimensional, podendo ser uma função de valor único (como no DEA), que incorpore todas as dimensões, inclusive um componente futurístico relativo à capacidade da empresa de enfrentar desafios.

Porém, de acordo ainda com os autores, os indicadores financeiros acabam sendo usados, uma vez que estão disponíveis e são compráveis, mesmo com a restrição de se ter apenas uma dimensão limitada de desempenho sendo mensurada.

A explicação do desempenho das empresas, segundo Brito e Brito (2005), é um dos principais desafios da área de gestão. A forma mais comum de medir 
esse sucesso é pela avaliação do desempenho financeiro. Mesmo quando se trata apenas do desempenho financeiro, continuam os autores, o desempenho tem uma natureza multidimensional, e essas dimensões podem ser objetivos conflitantes entre si, oferecendo dificuldades para a criação de um objetivo composto de desempenho.

Apesar de reconhecer todas as limitações aqui inseridas, o presente estudo parte para a avaliação do desempenho organizacional, tendo como base apenas variáveis financeiras. Porém, pelos motivos já expostos pelos autores anteriores, este não é o caso exclusivo de nosso estudo.

Em vários estudos, como os de Macedo e Macedo (2003), Brito e Vasconcelos (2003), Chan et al. (2003), Pohlmann e Corrar (2004), Bandeira de Mello e Marcon (2004), Borini et al. (2004), Omaki (2005), Gartner (2005), Santos e Casa Nova (2005) e Brito e Brito (2005), procura-se mensurar, analisar e avaliar o desempenho de empresas ou de unidades de negócio com a utilização de métodos multicriteriais. Assim sendo, a proposta deste artigo é apresentar e discutir uma modelagem alternativa àquelas já exploradas na literatura, no que tange à performance de empresas.

Numa análise desses trabalhos supracitados, verifica-se a existência de vários índices e, por conseguinte, vários enfoques que podem ser utilizados com o intuito de avaliar o desempenho de uma empresa, mas cada um desses terá sua importância em função dos objetivos de quem está analisando a eficiência organizacional. Por conta disso, se torna importante usar uma ferramenta que, de alguma forma, ajude ao analista a trabalhar com o conjunto de índices escolhidos por ele na busca por uma conclusão a respeito da performance da empresa.

Ao fazer uma análise da literatura de indicadores de desempenho ou de performance, disponíveis no EnANPAD de 2003, de 2004 e de 2005, no Encontro de Estudos em Estratégia (3E's) de 2003 e nas revistas RAE-eletrônica e RAC, pôde-se constatar que são vários os estudos que utilizam medidas financeiras como proxies de desempenho multidimensional, tal como está sendo proposto nesta pesquisa:

- Chan et al. (2003) e Pohlmann e Corrar (2004) elaboraram trabalhos em que o desempenho organizacional - num ambiente de privatizações no primeiro caso e numa análise de clusters no segundo - é feito utilizando variáveis tais como: receita, margem de lucro, retorno sobre o ativo e sobre o patrimônio líquido, grau de endividamento, liquidez corrente etc. No caso de Chan et al. (2003), a idéia era saber se existia diferença de desempenho antes e após a privatização em várias empresas utilizando variáveis contábil-financeiras. Já no estudo de Pohlmann e Corrar (2004), busca-se entender o compor- 
tamento e o desempenho de empresas pela evolução de uma série de indicadores contábil-financeiros.

- No estudo de Brito e Vasconcelos (2003), é proposto um estudo, por meio do uso de ferramentas estatísticas, dos dados de 252 empresas dos anos de I998 a 200I, para entender e prever a heterogeneidade de performance de empresas em função de variáveis de competitividade, tais como lucratividade operacional e ramo de atividade. Além desse estudo, Bandeira de Melo e Marcon (2004) fazem um trabalho com o mesmo foco, utilizando como indicadores os quocientes do EBITDA (Earnings Before Interest, Tax, Depreciation and Amortization) sobre o ativo total, do preço da ação no mercado sobre o valor contábil da ação e a diferença entre retorno sobre o patrimônio líquido e o custo de capital da empresa.

- O EBITDA é utilizado ainda como foco de análise de desempenho no trabalho de Borini et al. (2004), que utilizam, além de variáveis financeiras, variáveis estratégicas (subjetivas) para discriminar o desempenho de várias unidades de negócio subsidiárias de corporações multinacionais no Brasil.

- O estudo de Omaki (2005) teve como objetivo analisar se é possível estimar com razoável significância estatística medidas de desempenho financeiro de empresas dadas as médias das avaliações dos recursos intangíveis: reputação, know-how e cultura. Os resultados não permitem afirmar com razoável significância estatísticas em que é possível estimar medidas de desempenho financeiro, tais como margem líquida, rentabilidade do patrimônio líquido, nível de endividamento e liquidez corrente, a partir dos recursos intangíveis considerados.

- O artigo de Gartner (2005) buscou apresentar uma forma de mensuração do desempenho econômico-financeiro corporativo, agregando variáveis que descrevem o dinamismo competitivo (giro do ativo, rentabilidade operacional do ativo, rentabilidade operacional das vendas), a rentabilidade (rentabilidade líquida do ativo, rentabilidade do capital próprio e rentabilidade líquida das vendas) e o equilíbrio financeiro da empresa (liquidez corrente e endividamento geral). A metodologia proposta é sustentada pelos métodos de tomada de decisão multiatributo e permite que as empresas possam estabelecer parâmetros de desempenho para indicadores de mercado e financeiros, visando a subsidiar o planejamento de seus sistemas de avaliação balanceada de desempenho.

- O trabalho de Brito e Brito (2005) buscou analisar, de forma empírica, a relação de um dos fatores individuais das firmas, o seu tamanho, no desempenho financeiro. Esse estudo encontrou uma relação positiva entre tamanho e lucratividade (margem de EBIT - Earnings Before Interest and Tax e retor- 
no sobre o ativo) e uma relação quase inexistente entre tamanho e crescimento.

Em nenhum desses estudos se observou a utilização da ferramenta de DEA, ora proposta como base de análise neste trabalho. O estudo de Gartner (2005) é o que mais se aproxima deste, pois tem os mesmo princípios, apesar do uso de ferramentas distintas. Porém, outros dois trabalhos utilizaram a DEA como ferramenta para avaliação de desempenho multicriterial.

No trabalho de Macedo e Macedo (2003), um estudo com indicadores financeiros de unidades de negócio de uma empresa em nível nacional foi conduzido, no qual se concluiu que, do ponto de vista da eficiência, uma das formas de as empresas aumentarem seu potencial é a redução do excedente encontrado de cada input, dado o nível de output de cada unidade analisada. Os autores perceberam que as empresas eficientes e que se apresentam como benchmarks para as demais são aquelas que melhor combinam esses fatores.

O modelo apresentado pelos autores buscou a maximização da eficiência de cada empresa em análise, expressa pela razão entre saídas (índices de margem operacional e de giro em operação) e entradas (índices de sinistralidade e participação de capital de terceiros), pela comparação da eficiência de uma empresa em particular com o desempenho do grupo de empresas. A eficiência de Io०\% foi atingida por uma empresa quando comparações com outras organizações relevantes não mostraram evidência de ineficiência no uso dos inputs para alcançar os outputs. Os autores concluíram, ainda, que a metodologia empregada foi útil quando da existência de informações de várias empresas e quando se busca uma análise comparativa de suas eficiências.

Além desse trabalho, a pesquisa de Santos e Casa Nova (2005) apresentou um modelo estruturado de análise de demonstrações contábeis, baseado em DEA. Para tanto, foi desenvolvido um estudo de empresas do setor elétrico brasileiro, com dados obtidos da revista Melhores e Maiores da Exame, para os anos de I999 e 2000 , sobre as seguintes variáveis: outputs (valor adicionado, liquidez corrente, crescimento das vendas, aplicação no imobilizado) e inputs (PL ajustado e média de empregados). Os escores de eficiência obtidos pelo modelo foram ainda comparados com o indicador de excelência da revista e com o retorno sobre o patrimônio líquido. Os resultados apontaram para a complementaridade dos métodos de avaliação de desempenho, expandindo a compreensão dos fatores que influenciam a performance empresarial.

$\mathrm{Na}$ presente pesquisa, utilizaremos uma abordagem parecida com a destes dois últimos artigos, porém avaliaremos o desempenho de empresas diferentes e não de unidades de negócios de uma mesma empresa, como no caso de Macedo e Macedo (2003). Além disso, diferentemente do modelo DEA- 
VRS construído por Santos e Casa Nova (2005), neste estudo utilizaremos o modelo DEA-CRS, que se apresenta mais discriminante em relação ao desempenho.

\section{ANÁLISE DE DESEMPENHO EMM BANCOS}

De acordo com Antunes de Oliveira e Tabak (2004), com a globalização da competição, a indústria bancária tem experimentado uma nova maneira de pensar suas atividades, com conseqüente reflexo em seu nível de eficiência, principalmente com o uso de novas tecnologias no processamento da informação e no gerenciamento do risco. Assim sendo, mensurar a eficiência passa a ser um conceito-chave, e nesse contexto destaca-se a modelagem DEA.

Para Camargo Jr. et al. (2004), muitos fatores, tais como a globalização, a abertura dos mercados, o aumento dos investimentos em TI, dentre outros, vêm criando um novo cenário competitivo no setor bancário.

Brito et al. (2005) ressaltam que a busca por desempenho faz com que o setor bancário apareça como um dos mais evoluídos na economia brasileira. A tecnologia vem sendo utilizada maciçamente, e a evolução de processos e serviços tem tornado bancos públicos e privados cada vez mais eficientes.

Segundo Sathye (2002), a literatura sobre eficiência e produtividade em instituições financeiras é vasta. Em termos gerais, há duas metodologias para mensurar mudanças de produtividade: os econométricos (paramétricos) e os número-índices (não-paramétricos). A metodologia DEA é considerada como não-paramétrica, já que esta não requer a priori uma forma funcional da estrutura da tecnologia de produção.

De acordo com Camargo Jr. et al. (2004), os bancos são instituições de intermediação financeira que buscam auferir um ganho ou spread em operações que, de um lado, pagam uma certa remuneração a quem empresta recursos, recebendo, por outro lado, remuneração maior daqueles que necessitam de recursos. O ganho destas instituições está exatamente na prestação desses serviços de intermediação.

Uma questão relevante, destacada por Antunes de Oliveira e Tabak (2004), é como medir empiricamente as atividades dos bancos, que se dividem em: produzir serviços para depositantes e emprestadores; transformar o dinheiro do depositante em dinheiro emprestado ao tomador do crédito, gerenciando principalmente questões de liquidez e risco; gerenciar risco e processar informações. Assim sendo, os principais insumos seriam capitais humano, financeiro e físico e os principais produtos os montantes de recursos captados/emprestados e os serviços agregados. 
Os autores ressaltam que, de forma geral, as informações contábil-financeiras têm sido as mais utilizadas nos estudos sobre eficiência em bancos, além de informações operacionais, tais como número de empregados e de agências.

Para Al-Shammari e Salimi (I998), o setor bancário desempenha um papel fundamental dentro da economia, pois é um dos principais agentes financiadores das empresas em geral. Diante dessa importância é necessário que os bancos possam avaliar sua performance por meio de métodos consistentes para fornecer aos seus stakeholders informações confiáveis sobre seu desempenho.

A eficiência das instituições bancárias, ainda para os autores, tem sido avaliada por meio das tradicionais ferramentas de análise financeira, como a análise de índices contábil-financeiros. Entretanto, tem se tornado freqüente a utilização da técnica não-paramétrica conhecida como Análise Envoltória de Dados (DEA), devido à sua capacidade de prover dados de grande fidedignidade e de realizar comparações com outros bancos.

Alguns autores se destacam por seus estudos, tais como: Sherman e Gold (I985), Vassiloglou e Giokas (I990) e Drake e Howcroft (I994). Esses estudos consideravam a eficiência operacional bancária apenas focada nas saídas de serviços produzidos comparadas às entradas (insumos) consumidas. Ainda de acordo com Al-Shammari e Salimi (I998), no estudo de Fernandez-Castro e Smith (I994), foi apresentado um modelo não-paramétrico para análise da performance corporativa de natureza multidimensional utilizando-se índices contábil-financeiros. Estes são considerados inputs, se forem do tipo quanto menor melhor, e outputs, se forem do tipo quanto maior melhor.

O trabalho de Camargo Jr. et al. (2004) analisa e compara o desempenho de ig bancos comerciais e múltiplos de grande porte que atuavam no Brasil em 2003 , sob a abordagem DEA, considerando como inputs o ativo total, as despesas de pessoal e outras despesas administrativas, e como outputs as operações de crédito, as operações de crédito de longo prazo, as aplicações em tesouraria e a rentabilidade da atividade bancária. Os principais resultados obtidos nesse trabalho mostram que os bancos mais eficientes seriam aqueles com menores ativos totais, isto é, os bancos menores. Além disso, os bancos mais eficientes também são aqueles que conseguem realizar grandes operações de concessão de crédito de longo prazo.

O propósito do trabalho de Sathye (2002) é analisar as mudanças de produtividade em I7 bancos australianos entre I995 e I999, utilizando DEA. Os dados anuais são referentes a receitas operacionais e não-operacionais (outputs) e custos e despesas operacionais e não-operacionais (inputs).

O trabalho de Antunes de Oliveira e Tabak (2004) pretende mensurar e comparar a eficiência do setor bancário em diversos países, utilizando a metodologia de programação matemática não-paramétrica DEA. A amostra compreendeu 4I países desenvolvidos e emergentes, no período de I995 a 2002. 
Santos et al. (2004) apresentaram um trabalho com uma proposta de modelagem do problema de avaliação de performance. Por intermédio da utilização da DEA, buscou-se um índice (Índice de Performance Empresarial - IPE) capaz de conjugar indicadores financeiros e não-financeiros na análise de desempenho organizacional.

Fizeram parte da amostra da pesquisa I7 dos maiores bancos em operação no Brasil no ano de 2002 listados na revista Exame 500 Maiores e Melhores (2003). Os dados considerados foram obtidos na publicação acima e na revista Carta Capital edição especial sobre As Empresas mais Admiradas no Brasil (2002).

Os autores concluem que o modelo utilizado, desenvolvido a partir da DEA, foi capaz de conjugar em um único índice vários indicadores de naturezas diferentes (financeiros e não-financeiros) para a análise do desempenho organizacional. Além disso, os autores perceberam que a modelagem possuía as características de trabalhar diversas variáveis sem a necessidade de convertê-las para um padrão comum de unidade e de apoiar o processo decisório com uma técnica de natureza multicritério e, portanto, mais capaz de modelar a complexidade do mundo real.

O artigo de Lozano-Vivas et al. (200I) analisa a performance bancária na União Européia, primeiramente investigando a eficiência dos bancos em cada país e depois, com o uso de variáveis ambientais, analisando a eficiência geral em toda a Europa. Para alcançar esse objetivo, o estudo utiliza a modelagem DEA em mais de 600 bancos de ro países. As variáveis de output utilizadas foram os volumes de empréstimos, depósitos e outros ativos e como inputs os volumes de mãode-obra e estrutura física.

No estudo de Al-Shammari e Salimi (I998), o objetivo foi medir e comparar a performance financeira de alguns bancos, utilizando uma abordagem baseada no trabalho de Fernandez-Castro e Smith (I994), de modo a identificar aqueles que são eficientes e contribuir para a melhoria do desempenho das instituições ineficientes. Os dados obtidos, referentes a seis índices considerados como indicadores de desempenho válidos na análise de performance no setor bancário, foram organizados em quatro conjuntos, cada um representando o ano em que foram coletados (I99I-I994) e contando com I6 bancos de um total de I8, já que dois bancos foram retirados da análise por não apresentarem os dados necessários em alguns anos.

A maioria dos bancos mostrou um baixo desempenho quando comparados com aqueles considerados como unidades de benchmarking (eficiência igual a ı००\%). Uma análise bastante detalhada foi aplicada ao conjunto de dados composto pelas unidades eficientes, para que se pudesse chegar a um valor-referência para cada índice, que deveria ser alcançado para que as unidades ineficientes atingissem um alto desempenho. 
Barr et al. (2002) enfatizam que, durante as duas últimas décadas, muitos estudos foram realizados com o intuito de avaliar a eficiência das mais variadas instituições financeiras. Não é mera coincidência que esses estudos tenham se expandido exatamente num momento em que os mercados financeiros mundiais têm passado por muitas mudanças.

Os autores fizeram um trabalho sobre avaliação do desempenho relativo de alguns bancos comerciais norte-americanos no período de I984 a I998, no qual foi utilizada a metodologia DEA aplicada a dados provenientes de demonstrações de fim de ano. O modelo aplicado captura as funções de intermediação financeira essenciais de um banco e usa variáveis já empregadas em estudos semelhantes anteriores.

De uma forma geral, os bancos alocam recursos e controlam processos internos administrando seus empregados, instalações, despesas, e fontes e usos de fundos, enquanto trabalham para maximizar ativos e o retorno. Os bancos que melhor desempenham essa estratégia estão na fronteira eficiente, enquanto os bancos com muitas entradas ou poucas saídas em relação aos outros bancos são considerados relativamente ineficientes.

Os resultados revelaram que existem fortes e consistentes relações entre eficiência e algumas medidas independentes de desempenho. Segundo os autores, o modelo se mostrou útil para os bancos porque estabelecia um ponto de referência (benchmarking) com outras instituições, atuando como uma ferramenta de vigilância complementar no processo de verificação de desempenho.

\section{METODOLOGIA DO ESTUDO
EAPRESENTAÇÃO DOS DADOS}

Esta pesquisa pode ser caracterizada, de acordo com o exposto por Vergara (2004), como sendo descritiva e quantitativa, pois procura, por meio da aplicação da análise envoltória de dados às informações dos bancos de varejo, de atacado, de middle market e de financiamento que fazem parte da amostra, expor características a respeito da performance destes.

O processo de amostragem é não-probabilístico, pois parte de um universo naturalmente restrito, já que os bancos foram escolhidos a partir dos que constavam na publicação utilizada. Isso traz algumas limitações de inferência, mas não invalida os resultados da pesquisa, já que os bancos dessa listagem são, assumidamente, representativos de boas práticas gerenciais.

Esta pesquisa foi feita a partir de dados secundários colhidos na edição de junho de 2004 da revista Balanço Financeiro da Gazeta Mercantil sobre o de- 
sempenho dos melhores bancos e outras instituições financeiras. A pesquisa partiu dos bancos disponíveis na publicação, classificados em quatro tipos: de varejo, de atacado, de middle market e de financiamento. De posse dessas informações, retiraram aqueles bancos que já eram ineficientes de início, pois tinham rentabilidade negativa. Por fim, a amostra foi composta por 20 bancos de varejo, 34 de atacado, 2 I de middle market e 26 de financiamento.

Essa divisão por segmento se faz necessária por conta das diferentes atividades, em virtude do foco do negócio, exercidas pelos bancos de cada um destes. Isso ajuda a homogeneizar a amostra e fortalece, assim, a modelagem.

De cada um dos bancos selecionados, foram coletadas informações disponíveis referentes aos seguintes indicadores: liquidez imediata, inadimplência, eficiência operacional, rentabilidade do patrimônio líquido e custo operacional. A seguir, tem-se uma descrição sucinta de cada índice:

- Liquidez Imediata (LI): representa o output I e mede, em percentual, a divisão das disponibilidades, mais aplicações no mercado aberto, mais títulos e valores mobiliários do ativo circulante com os depósitos de curto prazo, mais as captações no mercado aberto do passivo circulante. Mostra a capacidade de pagamento de obrigações no curtíssimo prazo. É um índice do tipo quanto maior, melhor o desempenho.

- Rentabilidade do Patrimônio Líquido (RPL): representa o output 2 e mede, em percentual, a divisão do lucro líquido pelo patrimônio líquido. Mostra o retorno dos recursos investidos pelos acionistas após a apuração do lucro líquido. É um índice do tipo quanto maior, melhor o desempenho.

- Inadimplência (IND): representa o input I e mede, em percentual, a divisão dos créditos atrasados superiores a 60 dias sobre a carteira total de crédito. $\mathrm{O}$ índice mostra qual o percentual de créditos de difícil recebimento em relação à carteira de créditos total. É um índice do tipo quanto menor, melhor o desempenho.

- Eficiência Operacional (EOP): representa o input 2 e mede, em percentual, a divisão das despesas de pessoal e administrativas sobre o resultado bruto mais a receita de serviços. Mostra a incidência dos gastos operacionais no resultado da intermediação financeira mais as receitas de serviços. É um índice do tipo quanto menor, melhor o desempenho.

- Custo Operacional (COP): representa o input 3 e mede, em percentual, a divisão das despesas de pessoal e administrativas sobre o ativo total. Mostra a relação entre gastos de estrutura interna sobre o total de ativos. É um índice do tipo quanto menor, melhor o desempenho. 
Cada um desses indicadores representa um vetor de desempenho, já que é possível hierarquizar cada uma das instituições em relação a cada um deles individualmente. Esses seriam modelos de avaliação de performance monocriteriais. O que se busca neste artigo é apresentar uma metodologia multidimensional, baseada em DEA, na qual seja possível avaliar o desempenho de cada banco de modo multicriterial, ou seja, considerando de maneira integrada todos os vetores de desempenho apresentados.

Conforme destacado na revisão da literatura da seção 3 deste artigo, o uso apenas de variáveis financeiras nos estudos sobre desempenho organizacional, apesar de suas restrições, é amplamente feito. Sendo assim, as variáveis utilizadas no presente estudo podem ser consideradas representativas da performance empresarial, apesar das limitações naturalmente impostas.

Em linhas gerais, neste trabalho está sendo proposta uma abordagem que, a partir de informações sobre liquidez imediata, inadimplência, eficiência operacional, rentabilidade do PL e custo operacional de bancos em operação no Brasil, divididos em quatro segmentos distintos, procura medir a eficiência de cada banco em relação aos outros que fazem parte do mesmo segmento e que fazem parte da amostra.

Isso é feito por meio da utilização da DEA, que mostra quão eficiente um banco é no tratamento de seus inputs (inadimplência, eficiência operacional e custo operacional) e outputs (liquidez imediata e rentabilidade do patrimônio líquido), em relação aos outros.

Essa análise fornece um indicador que varia de ० a I ou de ०\% a I००\%, sendo que somente os bancos que obtêm índice de eficiência igual a um é que são efetivamente eficientes, ou seja, fazem parte da fronteira eficiente. Em termos práticos, o modelo procura identificar a eficiência de um banco comparando-o com os melhores desempenhos observados em seu nível de operação e segmento.

Em virtude da limitação de páginas não foi possível apresentar todos os dados coletados. Porém, o Quadro I mostra um resumo das informações pertinentes aos bancos, que fizeram parte da amostra final, por segmento:

Pode-se perceber que, no segmento de atacado, a LI tem uma dispersão muito grande, pois existem empresas com liquidez igual a zero até empresas com liquidez de mais de $3.000 \%$. O segmento de middle market possui os menores desvios em todas as variáveis exceto em EOP e COP, o que pode denotar diferenças significantes nessas variáveis entre os bancos do setor. Em relação aos valores médios, a variável EOP é que apresenta menor dispersão relativa (divisão do DP pela média), exceto no segmento de middle market. 
QUADRO I

\begin{tabular}{|c|c|c|c|c|c|c|}
\hline \multicolumn{7}{|c|}{ RESUMO DAS INFORMAÇOES POR SEGMENTO } \\
\hline \multicolumn{2}{|c|}{ SEGMENTOS / ÍNDICES } & LI & IND & EOP & RPL & $\mathrm{COP}$ \\
\hline \multirow[t]{5}{*}{ VAREJO } & Média & 76,19 & 6,19 & 70,92 & 18,10 & 8,87 \\
\hline & Maior & 384,20 & 15,60 & 122,90 & 37,20 & 21,50 \\
\hline & Menor & 7,00 & 0,70 & 40,80 & 5,40 & 4,30 \\
\hline & Mediana & 54,70 & 4,65 & 68,80 & 18,30 & 7,60 \\
\hline & DP & 75,87 & 4,22 & 19,09 & 9,51 & 4,33 \\
\hline \multirow{5}{*}{ ATACADO } & Média & 388,80 & 7,54 & 45,93 & 17,41 & 6,41 \\
\hline & Maior & 3306,90 & 94,80 & 99,00 & 42,70 & 41,20 \\
\hline & Menor & 0,00 & 0,00 & 9,10 & 0,10 & 0,50 \\
\hline & Mediana & 132,60 & 0,50 & 36,80 & 16,25 & 3,20 \\
\hline & DP & 688,63 & 18,14 & 26,18 & 11,15 & 9,16 \\
\hline \multirow{5}{*}{ MIDDLE MARKET } & Média & 78,02 & 2,44 & 70,33 & 15,65 & 6,68 \\
\hline & Maior & 202,20 & 7,40 & 456,10 & 26,70 & 42,30 \\
\hline & Menor & 40,50 & 0,10 & 22,40 & 1,50 & 0,70 \\
\hline & Mediana & 72,10 & 1,60 & 48,60 & 18,50 & 3,30 \\
\hline & DP & 34,54 & 1,99 & 88,50 & 7,45 & 8,75 \\
\hline \multirow[t]{5}{*}{ FINANCIAMENTO } & Média & 45,00 & 4,05 & 60,96 & 17,46 & 8,07 \\
\hline & Maior & 126,50 & 16,70 & 97,00 & 34,80 & 24,20 \\
\hline & Menor & 0,00 & 0,10 & 12,70 & 5,10 & 1,10 \\
\hline & Mediana & 34,90 & 2,30 & 62,65 & 14,60 & 7,10 \\
\hline & DP & 37,55 & 4,46 & 22,71 & 9,09 & 6,41 \\
\hline
\end{tabular}

No Quadro 2, tem-se uma listagem das instituições, por segmento, que fizeram parte da amostra analisada:

\section{QUADRO 2}

\section{BANCOS ANALISADOS EM CADA SEGMENTO}

\begin{tabular}{lc}
\hline $\begin{array}{l}\text { VAREJO } \\
\text { (20 DMUs) }\end{array}$ & $\begin{array}{r}\text { Bradesco, Itaú, Basa, ABN-Amro Bank, Banco do Brasil, Nossa Caixa, San- } \\
\text { tander, Caixa, Unibanco, BNB, Banrisul, HSBC, Banese, Banestes, BEP, } \\
\text { BESC, BMB, Sudameris, BRB e Banpará }\end{array}$ \\
\hline ATACADO & Pactual, BNP Paribrás, BBM, Votorantim, Modal, Rabobank, JP Morgan, \\
(34 DMUs) & Opportunity, PEBB, Safra, Fator, ING Bank, Guanabara, Alfa, Dresdner, \\
& CSFB, ABC Brasil, Crédit Lyonnais, Bank Boston, Morgan St Dean, Westlb, \\
& Citibank, J. Safra, Brascan, Capital, Tricury, UBS, Maxinvest, BPN Brasil, \\
& AGF, BNL, American Express, Matone e Ouroinvest
\end{tabular}




\section{QUADRO 2 (CONTINUAÇÃO)}

\section{BANCOS ANALISADOS EM CADA SEGMENTO}

MIDDLE MARKET Fibra, Credibel, Santos, Daycoval, Pine, Rendimento, Prosper, Sofisa, Bicban(21 DMUs) co, BVA, Tribanco, BMC, BRP, Schahin, Rural, Industrial, Indusv Multistock, Intercap, Paulista, Luso Brasileiro e Pottencial

FINANCIAMENTO

BGM, Cruzeiro do Sul, Honda, Dibens, Bancoob, Bansicredi, Toyota, Banco

(26 DMUs) Ibi, GM, Ford, Máxima, Paraná Banco, Gerdau, PSA Finance, Bonsucesso, Cacique, Pecúnia, A.J. Renner, Daimler-Chrysler, Cédula, BGN, Panamericano, Volkswagen, Rede, Ficsa e Morada

\section{APRESENTAÇÃO E ANÁLISE DOS RESULTADOS}

Com base nas informações dos bancos sob análise, montou-se o modelo de avaliação de eficiência para cada segmento bancário. Em todas as análises, utilizou-se uma orientação input e o modelo CRS, pois esta modelagem se mostra mais robusta na discriminação entre unidades eficientes e ineficientes.

Nessas quatro análises, estimou-se a eficiência de cada banco em relação aos outros de seu segmento. Para obter-se a eficiência de cada DMU, utilizouse um software de DEA, apresentado por Meza et al. (2003), denominado SIAD (Sistema Integrado de Apoio à Decisão - versão I.I). Os Quadros 3 a 6 mostram os resultados obtidos nesta análise para cada segmento. Além disso, foram analisadas as mudanças nos níveis de inputs e outputs nos bancos ineficientes para que se tornem eficientes.

\section{QUADRO 3}

\section{EFICIENCIA DOS BANCOS DE VAREJO}

\begin{tabular}{|c|c|c|c|}
\hline \multicolumn{4}{|c|}{ VAREJO } \\
\hline Bancos & Eficiência & Bancos & Eficiência \\
\hline - Bradesco & - $100,00 \%$ & - Banrisul & - $100,00 \%$ \\
\hline - Itaú Holding Fin & - $100,00 \%$ & - HSBC Bank Brasil & - $27,38 \%$ \\
\hline - Basa & - $100,00 \%$ & - Banese & - $62,17 \%$ \\
\hline - ABN-Amro Bank & - $53,08 \%$ & - Banestes & - $79,82 \%$ \\
\hline - Banco do Brasil & - $84,22 \%$ & - BEP & - $56,76 \%$ \\
\hline - Nossa Caixa & - $96,51 \%$ & - BESC & - $100,00 \%$ \\
\hline - Santander Brasil & - $95,01 \%$ & - $\mathrm{BMB}$ & - $34,88 \%$ \\
\hline - Caixa & - $100,00 \%$ & - Sudameris & - $26,41 \%$ \\
\hline - Unibanco & - $81,18 \%$ & - $\mathrm{BRB}$ & - $30,22 \%$ \\
\hline - BNB & - $100,00 \%$ & - Banpará & - $9,80 \%$ \\
\hline
\end{tabular}


Com base nessas informações, pode-se verificar, quanto ao desempenho, que apenas o Bradesco, Itaú, Basa, Caixa, BNB, Banrisul e BESC foram eficientes. Na verdade, esses bancos de varejo foram os que melhor combinaram os inputs (menores) e outputs (maiores).

No caso do segmento de varejo, bancos como o BMB, Sudameris, BRB e HSBC, aqueles com menor desempenho, necessitam de mudanças nos níveis de inputs e outputs superiores a $60 \%$ dos valores atuais. Já em instituições tais como a Nossa Caixa e o Santander, as mudanças são mínimas, pois estes têm altos níveis de eficiência.

\section{QUADRO 4}

\section{EFICIENCIA DOS BANCOS DE ATACADO}

\begin{tabular}{|c|c|c|c|}
\hline \multicolumn{4}{|c|}{ ATACADO } \\
\hline Bancos & Eficiência & Bancos & Eficiência \\
\hline - Pactual & - $100,00 \%$ & - Crédit Lyonnais & - $33,80 \%$ \\
\hline - BNP Paribas & - $100,00 \%$ & - BankBoston & $21,08 \%$ \\
\hline - BBM & - $57,63 \%$ & - Morgan St Dean & - $100,00 \%$ \\
\hline - Votorantim & $63,75 \%$ & - Westlb & - $21,99 \%$ \\
\hline - Modal & - $60,94 \%$ & - Citibank & - $15,23 \%$ \\
\hline - Rabobank & - $71,09 \%$ & - J.Safra & - $39,30 \%$ \\
\hline - JP Morgan & - $78,93 \%$ & - Brascan & - $12,57 \%$ \\
\hline - Opportunity & - $100,00 \%$ & - Capital & - $15,28 \%$ \\
\hline - $\mathrm{PEBB}$ & - $100,00 \%$ & - Tricury & $28,83 \%$ \\
\hline - Safra & $26,08 \%$ & - UBS & - $8,96 \%$ \\
\hline - Fator & - $36,74 \%$ & - Maxinvest & $21,76 \%$ \\
\hline - ING Bank & - $97,49 \%$ & - BPN Brasil & $22,44 \%$ \\
\hline - Guanabara & - $100,00 \%$ & - $A G F$ & - $16,37 \%$ \\
\hline - Alfa & - $14,90 \%$ & - BNL & - $5,85 \%$ \\
\hline - Dresdner Brasil & $33,23 \%$ & - American Express & - $8,52 \%$ \\
\hline - CSFB & - $41,31 \%$ & - Matone & - $4,65 \%$ \\
\hline - $A B C$ Brasil & - $36,55 \%$ & - Ourinvest & - $3,77 \%$ \\
\hline
\end{tabular}

Com base nessas informações, pode-se verificar, quanto ao desempenho, que apenas o Pactual, BNP Paribrás, Opportunity, PEBB, Guanabara e Morgan St Dean foram eficientes. Na verdade, esses bancos de atacado foram os que melhor combinaram os inputs (menores) e outputs (maiores). 
No segmento de atacado, bancos como UBS, BNL, American Express, Matone e Ouroinvest, que possuem índices de eficiência baixíssimos, necessitam de mudanças radicais. Já o ING Bank que tem índice muito próximo a Io०\% necessita de pequenas mudanças apenas nos indicadores de eficiência operacional e custo operacional.

\section{QUADRO 5}

\section{EFICIENCIA DOS BANCOS}

DE MIDDLE MARKET

\begin{tabular}{|c|c|c|c|}
\hline \multicolumn{4}{|c|}{ MIDDLE MARKET } \\
\hline Bancos & Eficiência & Bancos & Eficiência \\
\hline - Fibra & - 1 & - $\mathrm{BMC}$ & - 0,612659 \\
\hline - Credibel & - 0,875642 & - BRP & - 0,986735 \\
\hline - Santos & $\cdot 0,51675$ & - Schahin & - 0,305286 \\
\hline - Daycoval & - 1 & - Rural & - 0,376996 \\
\hline - Pine & - 1 & - Industrial & - 0,291485 \\
\hline - Rendimento & - 0,749149 & - Indusv Multistock & - 0,270302 \\
\hline - Prosper & - 1 & - Intercap & - 0,710058 \\
\hline - Sofisa & - 0,712795 & - Paulista & - 0,331666 \\
\hline - Bicbanco & - 0,540167 & - Luso Brasileiro & - 0,138485 \\
\hline - BVA & - 0,540269 & - Pottencial & - 0,036464 \\
\hline - Tribanco & - 0,90109 & & \\
\hline
\end{tabular}

Com base nessas informações, pode-se verificar, quanto ao desempenho, que apenas Fibra, Daycoval, Pine e Prosper foram eficientes. Na verdade, esses bancos de middle market foram os que melhor combinaram os inputs (menores) e outputs (maiores).

No caso dos bancos de middle market, como o BRP e o Tribanco, que possuem os maiores desempenhos diferentes de ı००\%, não existe a necessidade de grandes transformações para que estes passem a fazer parte da fronteira de eficiência. Porém bancos, tais como o Luso Brasileiro e Pottencial, necessitam de grande esforço no sentido de reduzir seus inputs e aumentar seus outputs (mudanças de cerca de $90 \%$ nos níveis atuais) para se tornarem I0०\% eficientes. 


\section{QUADRO 6}

\section{EFICIENCIA DOS BANCOS DE FINANCIAMENTO}

\begin{tabular}{|c|c|c|c|}
\hline \multicolumn{4}{|c|}{ FINANCIAMENTO } \\
\hline Bancos & Eficiência & Bancos & Eficiência \\
\hline - BGM & - $91,90 \%$ & - PSA Finance Brasil & - $71,61 \%$ \\
\hline - Cruzeiro do Sul & - $100,00 \%$ & - Bonsucesso & - $40,99 \%$ \\
\hline - Honda & - $100,00 \%$ & - Cacique & - $99,05 \%$ \\
\hline - Dibens & - $100,00 \%$ & - Pecúnia & - $52,53 \%$ \\
\hline - Bancoob & - $100,00 \%$ & - A.J.Renner & - $37,95 \%$ \\
\hline - Bansicredi & - $100,00 \%$ & - Daimlerchysler & - $34,85 \%$ \\
\hline - Toyota & - $100,00 \%$ & - Cédula & - $31,66 \%$ \\
\hline - Banco Ibi & - $65,77 \%$ & - Banco Bgn & $80,62 \%$ \\
\hline - General Motors & - $70,83 \%$ & - Panamericano & - $21,73 \%$ \\
\hline - Ford & - $64,16 \%$ & - Volkswagen & - $18,49 \%$ \\
\hline - Máxima & - $100,00 \%$ & - Rede & - $90,29 \%$ \\
\hline - Paraná Banco & - $52,42 \%$ & - Ficsa & - $21,26 \%$ \\
\hline - Gerdau & - $59,14 \%$ & - Morada & $8,85 \%$ \\
\hline
\end{tabular}

Baseado nessas informações, verifica-se, quanto ao desempenho, que os bancos Cruzeiro do Sul, Honda, Dibens, Bancoob, Bansicred, Toyota e Máxima foram eficientes. Esses bancos de financiamento foram os que melhor combinaram os inputs (menores) e outputs (maiores).

Nos bancos de financiamento, observou-se o mesmo comportamento já comentado nos outros segmentos. O banco Morada, por ser o de menor índice de eficiência, necessita de grandes mudanças em seus vetores de desempenho para se tornar eficiente. Já os bancos BGM, Cacique e Rede possuem índice próximo de I००\% e, por conta disso, não precisam de alterações profundas em seus atuais níveis de inputs e outputs.

Em cada um dos segmentos percebe-se que os melhores bancos são aqueles que possuem um desempenho multicriterial superior. Numa análise complementar, procurou-se verificar os índices ideais para cada banco não eficiente para que este pudesse atingir eficiência de ı००\%. Ou seja, uma análise que mostrasse a redução de inputs e/ou o incremento dos outputs necessários para que cada DMU se tornasse eficiente. A lógica é diminuir a inadimplência, o índice de eficiência operacional e o custo operacional e/ou aumentar a liquidez imediata e a rentabilidade do patrimônio líquido.

O que está exposto acima coloca a idéia de benchmarking, ou seja, a tentativa de tornar as DMUs ineficientes em eficientes usando estas últimas como referência para as primeiras. Conclui-se que alguns bancos necessitam de grandes transformações no que tange aos inputs e outputs. Porém alguns outros, para 
se tornarem eficientes, necessitam tão-somente de pequenas alterações no que diz respeito a seus inputs e/ou outputs.

Nota-se que vários bancos precisam melhorar bastante, exatamente aqueles que obtiveram os menores índices de eficiência. Porém os bancos com maiores eficiências (diferentes de I0०\%) precisam de pequenas alterações em seus indicadores para atingirem a performance máxima.

Por último, procedeu-se a uma análise dos pesos atribuídos aos vetores de desempenho para saber, com base em pesos iguais a zero, as variáveis que estavam sendo "desprezadas" na análise de desempenho. Em linhas gerais, quando uma variável tem peso ( $u$ ou v) igual a zero, isso representa que essas variáveis são naturalmente problemáticas na obtenção dos índices de eficiência.

Como a modelagem procura os melhores índices de desempenho, dadas as características de inputs e outputs, para cada DMU, esta atribui zero a toda variável que possa atrapalhar o objetivo de maximizar a eficiência. Tendo essa abordagem como referência, percebeu-se que as variáveis custo operacional (input) e liquidez imediata (output) eram as que mais apareciam com pesos zero em todos os segmentos. A exceção é no segmento de financiamento, que também apresenta a variável inadimplência com muitos pesos zero.

Isso significa que o custo operacional e a liquidez imediata são variáveis que podem ser melhoradas em todas as instituições e que estas não estão contribuindo objetivamente para a eficiência da grande maioria destas. No caso dos bancos de financiamento, por conta de seu foco de atuação, era de se esperar que a variável inadimplência fosse problemática.

\section{CONCLUSÕES E CONSIDERAÇÕES FINAIS}

A eficiência é um dos aspectos que vêm governando, em maior ou menor grau, dependendo da organização, a atuação de bancos e outras instituições financeiras no Brasil nos últimos anos.

Numa análise no segmento de varejo, percebe-se que bancos como Bradesco e Itaú, que são líderes do ranking (eficiência = Io০\%), são macroorganizações, com um claro processo de expansão por compra, fusão e/ou parcerias, que passaram a ter presença física e tecnológica em todo o país. As outras instituições líderes no varejo são grandes bancos públicos (Basa, Caixa, BNB, Banrisul e BESC).

Porém se percebe também que instituições de pequeno e médio porte possuem totais condições de sobrevivência e de competição. Esse é o caso, por exemplo, do Pactual, que é um dos líderes do ranking de atacado, do Fibra, que é líder no middle market, e do Cruzeiro do Sul, líder do segmento de financiamento. Isso ressalta o fato de que não é o tamanho que gera a competitividade, mas sim o desempenho superior. 
Numa análise geral, notamos que os modelos de DEA possibilitam realizar a mensuração da eficiência de unidades similares. Neste estudo, utilizou-se o modelo para avaliação da eficiência de bancos dos segmentos de varejo, atacado, middle market e de financiamento em operação no Brasil em 2003.

Os resultados desse estudo propõem uma nova percepção sobre a performance financeira de bancos que não se encontram disponíveis aos gestores e ao mercado em geral por meio dos balanços e tradicionais análises de índices financeiros.

Observa-se que a metodologia DEA é capaz de munir a alta administração dos bancos de informações adicionais sobre os maiores determinantes de eficiência ou ineficiência, partindo-se de variáveis pré-selecionadas, pois oferece uma análise de benchmarking, em que o gestor pode avaliar as alterações necessárias para que a instituição possa se tornar eficiente em termos competitivos.

Ou seja, a partir de informações que não estariam disponíveis pelas técnicas convencionais, os resultados da análise envoltória de dados podem proporcionar melhores condições de competitividade aos bancos, principalmente quando interpretadas e usadas com os conhecimentos e julgamentos próprios da alta administração sobre as operações de seus bancos.

Por intermédio da aplicação da Análise Envoltória de Dados são identificadas as unidades eficientes e ineficientes dentro de um conjunto de dados homogêneo, além da possibilidade de obter índices capazes de indicar quanto as unidades ineficientes precisam melhorar para se tornarem unidades eficientes. A taxa de eficiência não fornece apenas a ordenação dos bancos num ranking, mas também sugere o grau de ineficiência de um banco quando comparado com a unidade referencial de eficiência (benchmark).

Os modelos aplicados e discutidos possibilitam a comparação, em um sentido multidimensional, da capacidade com que cada unidade (DMU) transforma seus "insumos" em "produtos" e, ainda, informam alterações que devem ser realizadas no nível de utilização de insumos e de produtos, para tornar unidades ineficientes em eficientes.

De posse dos dados apresentados, pode-se criar um ranking, entre esses bancos analisados, levando em consideração uma situação de análise que pondera simultaneamente múltiplos elementos importantes do desempenho organizacional. Numa comparação entre a análise de desempenho feita pela Gazeta Mercantil e pelo DEA neste artigo, percebe-se que em todos os segmentos os primeiros colocados do ranking da Gazeta obtiveram índice de eficiência igual a Io०\% ou próximos a esse valor. Além disso, observou-se uma correlação relativamente grande e significativa entre os índices de desempenho obtidos pelos dois modelos. A título de ilustração a revista utiliza uma metodologia baseada em pesos preestabelecidos, atribuídos aos índices para encontrar o total de pontos de cada banco.

Este assunto não se encontra encerrado, pois ainda há muito a ser explorado desta metodologia em gestão de instituições financeiras. Este mesmo traba- 
lho deve ter continuidade por meio de uma melhor visão dos vetores de desempenho que mais contribuem para uma mensuração mais apurada da eficiência organizacional. Além disso, sugerem-se novos estudos utilizando esta ou outras modelagens DEA, para outros setores ou para outros problemas, como os de localização de unidades produtivas ou centros de distribuição, seleção de fornecedores, dentre outros.

\section{REFERÊNCIAS}

AL-SHAMMARI, M.; SALIMI, A. Modeling the operating efficiency of banks. Logistics Information Management, v. II, n. I, p. 5-I7, I998.

ANTUNES DE OLIVEIRA; C. V.; TABAK, B. M. Comparativo da eficiência bancária utilizando Data Envelopment Analysis (DEA). In: ENCONTRO NORTE-NORDESTE DE FINANÇAS, I., 2004, Recife. Anais do I ENEFIN. Recife: FIR, 2004. I CD.

BANDEIRA DE MELO, R.; MARCON, R. A mensuração multivariada da performance e suas componentes de variância: uma análise dos efeitos do ano, indústria e firma no contexto brasileiro. In: ENCONTRO DA ASSOCIAÇÃO NACIONAL DE PÓS-GRADUAÇÃO E PESQUISA EM ADMINISTRAÇÃO, 28., 2004, Curitiba. Anais do XXVIII ENANPAD. Curitiba: ANPAD, 2004. I CD.

BANKER, R. D.; CHARNES, A.; COOPER, W. W. Some models for estimating technical and scale inefficiencies in data envelopment analysis. Management Science, v. 30, n. 9, p. I078-I092, I984.

BARR, R. S.; KILLGO, K. A.; SIEMS, T. F.; ZIMMEL, S. Evaluating the productive efficiency and performance of U.S. commercial banks. Managerial Finance, v. 28, n. 8, p. 3$25,2002$.

BORINI, F. M.; LUCCHESI, E. P.; OLIVEIRA Jr., M. M.; GUEVARA, A. J. H.; PROENÇA, E. R. Estratégia e desempenho financeiro das subsidiárias de corporações multinacionais no Brasil. In: ENCONTRO DA ASSOCIAÇÃO NACIONAL DE PÓS-GRADUAÇÃO E PESQUISA EM ADMINISTRAÇÃO, 28., 2004, Curitiba. Anais do XXVIII ENANPAD. Curitiba: ANPAD, 2004. I CD.

BRITO, E. P. Z.; CAMPOS, L. A.; BRITO, L. A.; THOMAZ, J. C. Reputação corporativa e desempenho: uma análise empírica no setor bancário. In: ENCONTRO DA ASSOCIAÇÃO NACIONAL DE PÓS-GRADUAÇÃO E PESQUISA EM ADMINISTRAÇÃO, 29., 2005, Brasília. Anais do XXIX ENANPAD. Brasília: ANPAD, 2005. I CD.

BRITO, L. A. L.; BRITO, E. P. Z. Tamanho e desempenho financeiro. In: ENCONTRO DA ASSOCIAÇÃO NACIONAL DE PÓS-GRADUAÇÃO E PESQUISA EM ADMINISTRAÇÃO, 29., 2005, Brasília. Anais do XXIX ENANPAD. Brasília: ANPAD, 2005. I CD. - VASCONCELOS, F. C. A heterogeneidade da performance, suas causas e o conceito de vantagem competitiva: proposta de uma métrica. In: ENCONTRO DE ESTUDOS EM ESTRATÉGIA, I., 2003, Curitiba. Anais do I Encontro de Estudos em Estratégia. Curitiba: ANPAD, 2003. I CD. 
A influência do país de origem no desempenho das empresas. Revista de Administração Contemporânea, v. 9, n. 4, p. 97-II8, 2005.

CAMARGO Jr., A. S.; MATIAS, A. B.; MARQUES, F. T. Desempenho dos bancos comerciais e múltiplos de grande porte no Brasil. In: CONGRESSO LATINO-AMERICANO DE CHARNES, A.; COOPER, W. W. Programming with Linear Fractional Functionals. Naval Research Logistic Quarterly. v. 9, p. 18I-186, I962.

ESCOLAS DE ADMINISTRAÇÃO, 39., 2004, San Domingo, República Dominicana. Anais do XXXIX CLADEA. San Domingo/República Dominicana: CLADEA, 2004. I CD. CHAN, B. L.; CORRAR, L. J.; MARTINS, G. A. Avaliação da privatização brasileira sob a ótica do desempenho operacional e financeiro. In: ENCONTRO DA ASSOCIAÇÃO NACIONAL DE PÓS-GRADUAÇÃO E PESQUISA EM ADMINISTRAÇÃO, 27., 2003, Atibaia. Anais do XXVII ENANPAD. Atibaia: ANPAD, 2003. I CD.

CHARNES, A.; COOPER, W. W.; RHODES, E. Measuring the efficiency of decision making units. European Journal of Operational Research, v. 2, n. 6, p. 429-444, 1978.

— - — LEWIN, A. Y.; SEIFORD, L. M. Data envelopment analysis. 2. ed. Boston: KAP, I994.

COELLI, T.; RAO, D. S. P.; BALTESE, G. E. An introduction to efficiency and productivity analysis. Boston: KAP, 1998.

CROZATTI, J.; GUERREIRO, R. O uso de conceitos de mensuração e avaliação de desempenho em relatórios gerenciais e a relação com indicadores financeiros de desempenho: um estudo em companhias abertas brasileiras. In: CONGRESSO DEL INSTITUTO INTERNACIONAL DE COSTOS, 8., 2003, Punta del Leste, Uruguai. Anais do VIII Congresso del IIC. Punta del Leste, Uruguai: IIC, 2003. I CD.

DRAKE, L.; HOWCROFT, B. Relative Efficiency in the Branch Network of a UK Bank: an empirical study. OMEGA. v. 22, n. I, p. 83-90, I994.

FARIA, L. H. L.; BRANDÃO, M. M.; GOMES E SILVA, V. Uma contribuição ao estudo da performance através de suas componentes de variância: introduzindo a variável explanatória grupo estratégico. In: ENCONTRO DA ASSOCIAÇÃO NACIONAL DE PÓS-GRADUAÇÃO E PESQUISA EM ADMINISTRAÇÃO, 29., 2005, Brasília. Anais do XXIX ENANPAD. Brasília: ANPAD, 2005. I CD.

FERNANDEZ-CASTRO, A.; SMITH, P. Towards a General Non-Parametric Model of Corporate Performance. OMEGA. v. 22, n. 3, p. 237-49, I994.

GARTNER, I. R. Metodologia alternativa para avaliação do desempenho e risco econômico-financeiro de empresas. In: ENCONTRO DA ASSOCIAÇÃO NACIONAL DE PÓSGRADUAÇÃO E PESQUISA EM ADMINISTRAÇÃO, 29., 2005, Brasília. Anais do XXIX ENANPAD. Brasília: ANPAD, 2005. I CD.

KAPLAN, R. S.; NORTON, D. P. Estratégia em ação. Rio de Janeiro: Campus, I997.

LINS, M. P. E.; MEZA, L. Â. Análise envoltória de dados e perspectivas de integração no ambiente de apoio à decisão. Rio de Janeiro: COPPE/UFRJ, 2000.

LOZANO-VIVAS, A.; PASTOR, J. T.; HASAN, I. European bank performance beyond country borders: what really matters? European Finance Review, v. 5, n. I-2, p. I4I-I65, 200 I. MACEDO, M. A. S. A utilização da análise envoltória de dados (DEA) na consolidação de medidas de desempenho organizacional. In: CONGRESSO BRASILEIRO DE CUSTOS, II, 
- DESEMPENHO ORGANIZACIONAL NO SETOR BANCÁRIO BRASILEIRO •

MARCELO ALVARO DA SILVA MACEDO • RODRIGO MELO SANTOS • FABRÍCIA DE FARIAS DA SILVA

2004, Porto Seguro. Anais do XI Congresso Brasileiro de Custos. Porto Seguro: ABC, 2004a. I CD.

Indicadores de desempenho: uma contribuição para o monitoramento estratégico através do uso de análise envoltória de dados (DEA). In: SIMPÓSIO DE ADMINISTRAÇÃO DA PRODUÇÃO, LOGÍSTICA E OPERAÇÕES INTERNACIONAIS, 7., 2004, São Paulo. Anais do VII SIMPOI. São Paulo: FGVSP, 2004b. I CD.

; MACEDO, H. D. R. Avaliação de performance financeira através da análise envoltória de dados: um estudo de caso em unidades de negócio. In: CONGRESSO LATINO-AMERICANO DE ESCOLAS DE ADMINISTRAÇÃO, 38., 2003, Lima, Peru. Anais do XXXVIII CLADEA. Lima, Peru: CLADEA, 2003. I CD.

MACHADO, M. R.; MACHADO, M. A. V.; CELESTINO, M., PAULO, E.; LOPES, J. E. G. Avaliação de resultado e desempenho: um estudo comparativo entre Balanced Scorecard e Gecon. In: CONGRESSO DEL INSTITUTO INTERNACIONAL DE COSTOS, 8., 2003, Punta del Leste, Uruguai. Anais do VIII Congresso del IIC. Punta del Leste, Uruguai: IIC, 2003. I CD.

MEZA, L. A.; BIONDI NETO, L.; SOARES DE MELLO, J. C. C. B.; GOMES. E. G.; COELHO, P. H. G. SIAD - Sistema Integrado de Apoio à Decisão: uma implementação computacional de modelos de análise de envoltória de dados. In: SIMPÓSIO DE PESQUISA OPERACIONAL DA MARINHA, 6., 2003, Rio de Janeiro. Anais do VI SPOLM. Rio de Janeiro: CASNAV, 2003. I CD.

OMAKI, E. T. Recursos intangíveis e desempenho em grandes empresas brasileiras: avaliações dos recursos intangíveis como estimadores de medidas de desempenho financeiras. In: ENCONTRO DA ASSOCIAÇÃO NACIONAL DE PÓS-GRADUAÇÃO E PESQUISA EM ADMINISTRAÇÃO, 29., 2005, Brasília. Anais do XXIX ENANPAD. Brasília: ANPAD, 2005. I CD.

POHLMANN, M. C.; CORRAR, L. J. Análise cluster de setores da economia brasileira utilizando indicadores contábeis. In: ENCONTRO DA ASSOCIAÇÃO NACIONAL DE PÓS-GRADUAÇÃO E PESQUISA EM ADMINISTRAÇÃO, 28., 2004, Curitiba. Anais do XXVIII ENANPAD. Curitiba: ANPAD, 2004. I CD.

REVISTA BALANÇO FINANCEIRO. São Paulo: Gazeta Mercantil, 2004. Anual. O desempenho dos melhores: o ranking dos 400 maiores.

SANTOS, A.; CASA NOVA, S. P. C. Proposta de um modelo estruturado de análise de demonstrações contábeis. Revista de Administração de Empresas - Eletrônica, v. 4, n. I, art. 8, 2005. Disponível em: http://www.rae.com.br/eletronica. Acesso em: 2 maio 2006. SANTOS, R. M.; MACEDO, M. A. S.; SILVA, F. F. Avaliação de performance de bancos no Brasil. In: ENCONTRO NORTE-NORDESTE DE FINANÇAS, I, 2004, Recife. Anais do I ENEFIN. Recife: FIR, 2004. I CD.

SATHYE, M. Measuring productivity changes in Australian banking: an application of Malmquist índices. Managerial Finance, v. 28, n. 9, p. 48-59, 2002.

SHERMAN, H. D.; GOLD, F. Bank Branch Operating Efficiency: evaluation with data envelopment analysis. Journal of Banking Finance. v. 9, June, p. 297-315, I985.

SOTERIOU, A. C.; ZENIOS, S. A. Using data envelopment analysis for costing bank products. European Journal of Operational Research, v. II4, n. 2, p. 234-248, I999. 
VASSILOGLOU, M.; GIOKAS, D. A Study of the Relative Efficiency of Bank Branches: an application of data envelopment analysis. Journal of the Operational Research Society. v. 4I, n. 7, p. 59I-7, I990.

VERGARA, S. C. Projetos e relatórios de pesquisa em administração. 5. ed. São Paulo: Atlas, 2004.

WANDERLEY, C. A.; MEIRA, J. M.; MIRANDA DA SILVA, A. C.; MIRANDA, L. C. Um estudo sobre indicadores de desempenho para a perspectiva do aprendizado e crescimento do balanced scorecard. In: CONGRESSO DEL INSTITUTO INTERNACIONAL DE COSTOS, 8., 2003, Punta del Leste, Uruguai. Anais do VIII Congresso del IIC. Punta del Leste, Uruguai: IIC, 2003. I CD.

ZHU, J. Multi-factor performance measure model with application to fortune $500 \mathrm{com}$ panies. European Journal of Operational Research, n. I23, n. I, p. I05-I24, 2000.

\section{TRA MITAÇ ÃO}

Recebido em 22/3/2006

Aprovado em 26/5/2006 
Copyright of Revista de Administração Mackenzie is the property of Universidade Presbiteriana Mackenzie, RAM-Revista de Administracao Mackenzie and its content may not be copied or emailed to multiple sites or posted to a listserv without the copyright holder's express written permission. However, users may print, download, or email articles for individual use. 